\title{
Ferramenta de programação neurolinguística para intermediação de conflitos ambientais
}

Em uma era onde o desenvolvimento de um país muitas vezes está atrelado a implantação de grandes indústrias e empreendimentos, os impactos ambientais, positivos e negativos, aparecem e vem acompanhados de notórios conflitos. Devido a sua complexidade e importância, os estudos sobre esses conflitos ambientais tornaram-se relevantes e necessários nas últimas décadas. Muitas vezes os conflitos podem ser amenizados por processos de comunicação eficientes. A programação neuroliguística (PNL) traz ferramentas que podem gerar transformações nestes relacionamentos. O objetivo deste projeto foi desenvolver uma ferramenta para a resolução de conflitos ambientais e melhoria da comunicação, utilizando a PNL. A metodologia se consistiu em 4 fases: criação da ferramenta a partir dos conceitos de PNL, estruturação da mesma em formato de cartilha, aplicação do material desenvolvido em 3 simulações para validação da ferramenta e avaliação a melhoria dos relacionamentos. Ao total, foram aplicados 83 questionários, respondidos por 3 grupos, participantes da dinâmica de negociação, avaliadores externos ferramenta e avaliação a melhoria dos relacionamentos. Ao total, foram aplicados 83 questionários, respondidos por 3 grupos, participantes da dinâmica de negociação, avaliadores externos a dinâmica e especialistas na área de PNL e gestão de conflitos ambientais. Após as análises pode-se afirmar que a ferramenta proporcionou a melhoria na resolução de conflitos ambientais e na comunicação entre os diversos atores. É importante levar em consideração que a ferramenta foi aplicada em simulações de conflito, apresentando uma primeira perspectiva dos

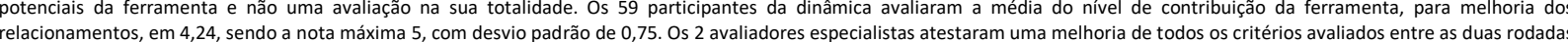
de negociaç̃o, com e sem a ferramenta desenvolvida. Já os 18 avaliadores externos a dinâmica, eliminaram possíveis indícios de tendenciosidade e corroboraram com os resultados dos demais a

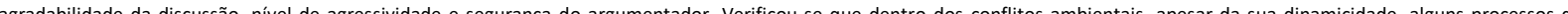
comunicação são comuns a todas as negociações e se bem trabalhados podem auxiliar na melhoria dos relacionamentos e resolução dos conflitos. Apesar da complexidade e individualidade de cada conflito, uma ferramenta que possibilita a melhoria das discussões sobre estes temas é um passo inicial para auxiliar e abrir portas frente a esses desafios.

Palavras-chave: Ferramenta de comunicação; Negociação ambiental; PNL.

\section{Neurolinguistic programming tool for intermediation of environmental conflicts}

\begin{abstract}
In an era where the development of a country is often linked to the implantation of large industries and enterprises, the environmental impacts, positive and negative, appear and are accompanied by notorious conflicts. Due to its complexity and importance, studies on these environmental conflicts have become relevant and necessary in recent decades. Conflicts can often be mitigated by efficient communication processes. Neuroliguistic Programming (NLP) brings tools that can generate changes in these relationships. The objective of this project was to develop a tool for resolving environmental conflicts and improving communication, using NLP. The methodology consisted of 4 phases: creation of the tool based on NLP concepts, structuring it in a booklet format, application of the material developed in 3 simulations to validate the tool and assess the improvement of relationships. In total, 83 questionnaires were applied, answered by 3 groups, participants in the negotiation dynamic, external evaluators and experts in the area of NLP and environmental conflict management. After the analysis, it can be said that the tool provided an improvement in the resolution of environmental conflicts and in the communication between the different actors. It is important to take into account that the tool was applied in conflict simulations, presenting a first perspective of the tool's potentials and not an evaluation in its entirety. The 59 participants in the dynamic evaluated the average the too criteria evaluated between the two rounds of negotiation bias and corroborated with the results of the other evaluators, attesting the help of the tool for the resolution of environmental conflicts. According to this last group, the improvements were more felt in the criteria of pleasantness of the discussion, level of aggressiveness and security of the argumentative. It was found that within environmental conflicts, despite their dynamism, some communication processes are common to all negotiations and if well worked, they can help improve relationships and resolve conflicts. Despite the complexity and individuality of each conflict, a tool that makes it possible to improve discussions on these topics is an initial step to assist and open doors in the face of these challenges.
\end{abstract}

Keywords: Communication tool; Environmental negotiation; NLP.

Topic: Desenvolvimento, Sustentabilidade e Meio Ambiente

Reviewed anonymously in the process of blind peer.

Najla Cristina Cardoso El Ghoz (iD

Universidade Federal do Paraná, Brasil

http://lattes.cnpq.br/9920595416764236

http://orcid.org/0000-0003-4910-1710

naj.cristina@gmail.com

Paulo de Tarso de Lara Pires (iD

Universidade Federal do Paraná, Brasil

http://lattes.cnpq.br/0670032752534789

http://orcid.org/0000-0001-9260-540X

ptlpires@gmail.com

\section{Marielle Feilstrecker (iD}

Universidade Federal de Santa Catarina, Brasil

http://lattes.cnpq.br/2231162832626932

http://orcid.org/0000-0003-1969-0016

mariellefr@hotmail.com

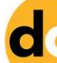

DOI: 10.6008/CBPC2179-6858.2020.004.0026
Received: 10/05/2020

Approved: 04/06/2020
Referencing this:

GHOZ, N. C. C. E.; PIRES, P. T. L.; FEILSTRECKER, M.. Ferramenta de programação neurolinguística para intermediação de conflitos ambientais. Revista Ibero-Americana de Ciências Ambientais, v.11, n.4, p.316-330, 2020. DOI: http://doi.org/10.6008/CBPC2179$\underline{6858.2020 .004 .0026}$ 


\section{INTRODUÇÃO}

Os conflitos ambientais têm tomado forma e relevância na sociedade atual. Com isso, as esferas de comunicação e a informação sobre questões ambientais vem sendo popularizadas, fazendo com que as comunidades estejam mais atentas, participativas e envolvidas nas questões que as cercam. Ao mesmo tempo que a informação tem veiculado com maior facilidade, a sua transmissão e interpretação podem sofrer processos de distorção ou manipulação, gerando conflitos ou desentendimentos, os quais também estão diretamente relacionados aos interesses de cada grupo.

Grande parte dos relacionamentos entre as indústrias que possuem impactos ambientais relevantes e as comunidades situadas no seu entorno são conturbados. É necessário observar com cautela os padrões de comunicação envolvidos neste relacionamento, pois, segundo O'Connor (2015), toda transferência de informação através da comunicação possui traços de generalização, distorção e omissão.

Diante deste cenário, a programação neurolinguística (PNL), que tem por objetivo estudar comportamentos, pensamentos e padrões de comunicação, surge como alternativa para: a proposição de novas ferramentas de entendimento entre as partes envolvidas no conflito e a construção de um relacionamento baseado em confiança e clara comunicação. Este trabalho buscou desenvolver uma ferramenta para minimizar conflitos e melhorar a comunicação entre empreendimentos com impacto ambiental e comunidades, baseada na programação neurolinguística.

\section{REVISÃO TEÓRICA}

\section{Programação neurolinguística}

O’Connor (2015) indicou que a programação neurolinguística pode ser entendida como o estudo dos comportamentos e da excelência humana, no qual existe a possibilidade de promover rápidas e positivas mudanças por meio da utilização de padrões linguísticos de comportamentos e pensamentos. Bandler et al. (1982) definem a PNL como um modelo poderoso e explicito de experiências humanas e de comunicações entre as pessoas. A PNL permite o acesso aos comportamentos e processos de pensamento de performers eficazes e ao copiá-los é possível ser igualmente bem-sucedido (ANDREAS, 1999). Dowlen (1996) citou que as habilidades desenvolvidas por meio da PNL incluem a capacidade de definir resultados positivos, entender como os outros percebem circunstâncias específicas e perceber quando o pensamento está ocorrendo em imagens, sons ou sentimentos. Dilts (1998) constatou que os três componentes que mais influenciam na geração das experiências humanas são a neurologia, a linguagem e a programação.

Algumas ferramentas e conteúdos utilizados pela programação neurolinguística podem ser amplamente observadas e aplicadas quando o quesito é comunicação facilitada e bom relacionamento (O'CONNOR et al., 1996). Nesta pesquisa foram abordados principalmente os conteúdos: Suavizadores linguísticos, Posições perceptuais, Sistemas representacionais, Estados internos emocionais, Ressignificação, Rapport ou empatia, Metamodelo, Valores e critérios de valores, Teoria do cérebro triuno. 


\section{Conflito e impacto socioambiental}

Dentre as diversas definições para impacto ambiental, Wathern (1988) define impacto ambiental como a mudança em um parâmetro ambiental, num determinado período e numa determinada área, que resulta de uma dada atividade, comparada com a situação que ocorreria se essa atividade não tivesse sido iniciada. Já a NBR ISO 14.001, define impacto ambiental como qualquer modificação do meio ambiente, adversa ou benéfica, que resulte, no todo ou em parte, dos aspectos ambientais da organização (ABNT, 2015).

Ortiz (1999) definiu conflito socioambiental como uma situação social, onde dois ou mais lutam ao mesmo tempo para obter o mesmo conjunto de recursos escassos. Também afirmou que os conflitos sobre recursos naturais são fenômenos sociais que envolvem condições mínimas, como escassez, deterioração ou privação. Fonseca et al. (2012) apontaram algumas características que devem ser encontradas na caracterização de um conflito ambiental, sendo elas, os atores sociais, a natureza do conflito, o objeto de disputa e as dinâmicas (escala e temporalidade).

Suárez et al. (2015) afirmaram que os conflitos ambientais decorrem não só de um impacto ambiental, mas também de uma ação social coletiva em torno desses impactos. Conforme afirmaram Nascimento et al. (2002) os conflitos existem desde o início da humanidade, fazem parte do processo de evolução dos seres humanos e são necessários para o desenvolvimento e o crescimento de qualquer sistema familiar, social, político e organizacional. Ortiz (1999) e Arias (1999) concordaram com esta visão e apontam que se deve parar de olhar para o conflito como algo negativo em si, porque o conflito também pode ser um gerador de mudança social que só precisa ser bem administrado. Segundo Wanderley (2008) devido a sua complexidade e importância, o estudo sobre conflitos ambientais se transformou num dos principais focos analíticos e metodológicos da ecologia política.

\section{METODOLOGIA}

Este estudo foi desenvolvido por meio de quatro fases principais que consistem na identificação de conteúdo, criação, validação e avaliação de uma ferramenta para auxiliar na melhoria do relacionamento e gerenciamento de conflitos entre diferentes partes interessadas. A ferramenta desenvolvida considerou como principais atores de conflitos ambientais os representantes de empreendimentos que possuem relevante impacto ambiental e as comunidades situadas próximas a eles. As etapas metodológicas seguidas para realização do trabalho estão apresentadas na Figura 1.

A primeira fase de desenvolvimento desta pesquisa consistiu na determinação dos principais conteúdos de PNL que poderiam ser aplicadas ao contexto dos encontros empresa/comunidade. Os conteúdos de PNL que foram identificados nas diversas fontes da pesquisa bibliográfica foram catalogados em uma lista. As pesquisas de conteúdo contemplaram as fontes: artigos científicos, livros escritos pelos criadores da PNL, apostilas de formações de neuroliguística, guias e roteiros de cursos importantes na área. Os critérios de escolha subjetivos levados em consideração foram: alto grau de importância nos processos 
de comunicação, inter-relação na sua aplicação e facilidade de simplificação dos conceitos para repassar o conhecimento aos demais grupos envolvidos na situação.

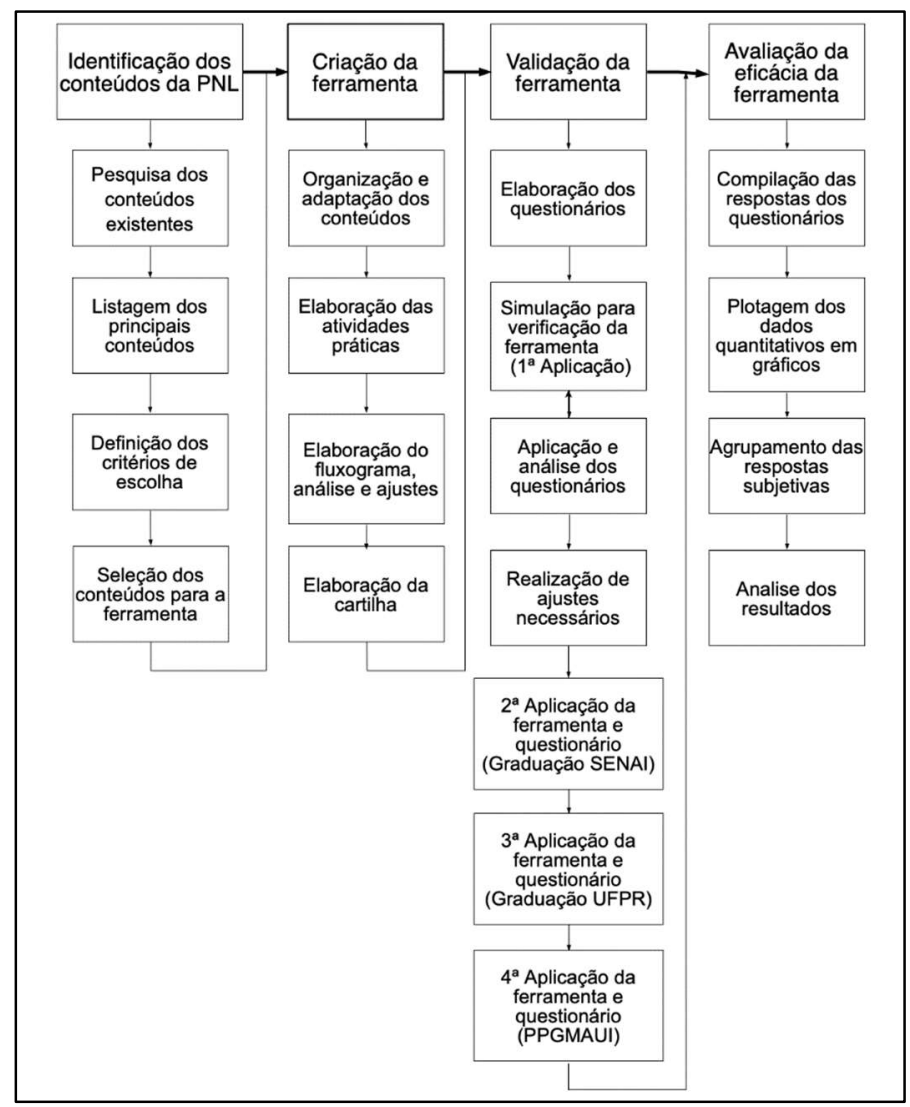

Figura 1: Fluxograma de desenvolvimento da pesquisa.

A segunda fase abrangeu a criação de uma ferramenta, baseada nos conteúdos de PNL selecionados, para o auxílio nos processos de comunicação que ocorrem nos encontros e reuniões entre os diferentes atores já delimitados (empreendimentos e comunidade do entorno). A partir daí foi definido que a ferramenta respeitaria três partes principais na sua estrutura: a caracterização do problema pelos grupos, a preparação da argumentação e a sua execução durante o processo de negociação. A próxima etapa desta fase consistiu na elaboração das atividades práticas que iriam suportar a ferramenta. Baseado nos conceitos teóricos de cada conteúdo e nos exemplos descritos no material bibliográfico para cada assunto foi criada a primeira versão das atividades práticas que iriam compor a ferramenta. Na terceira etapa, a ferramenta foi estruturada em fluxograma para visualização sistêmica das suas entradas e saídas, bem como verificação de sua sequência lógica. A quarta etapa desta fase consistiu na transcrição e detalhamento das atividades práticas em uma cartilha, de modo a facilitar a utilização da mesma durante os processos de negociação. Neste processo foi importante levar em consideração a linguagem utilizada na cartilha. Pois, para que ela atenda o objetivo proposto, a mesma deveria ser facilmente entendida e interpretada por qualquer cidadão brasileiro alfabetizado.

Após a criação da ferramenta a fase seguinte consistiu na sua validação. Para sua validação, foram realizadas 3 simulações de uso da ferramenta, seguidas de avaliações através de questionários. De forma mais detalhada, a primeira etapa desta fase compôs a elaboração de 3 questionários diferentes. De modo a 
cada um deles atender melhor os avaliadores da ferramenta. Foram eles, os alunos participantes da simulação, dois especialistas, um na área de gestão de conflitos ambientais outro em programação neurolinguística e 18 avaliadores externos, pessoas que não participaram ou acompanharam a dinâmica de aplicação, contemplando 8 professores e 10 mestres de diferentes instituições e formações em diversas áreas do conhecimento. Na sequência à foi realizada definição do tamanho da amostra a ser avaliada em relação ao universo populacional da Universidade Federal do Paraná (UFPR), utilizando para tal a fórmula de cálculo amostral para populações infinitas:

$$
\begin{array}{r}
n=\frac{\left[Z_{\propto / 2}\right]^{2} \cdot 0,25}{E^{2}} \\
n=\text { Número de indivíduos na amostra } \\
Z_{\propto / 2}=\text { Valor crítico que corresponde ao grau de confiança desejado } \\
E=\text { Margem de erro ou erro amostral da estimativa }
\end{array}
$$

Assumindo os seguintes parâmetros: $13 \%$ de erro amostral e $95 \%$ de probabilidade (valor crítico: 1,96) e o número de alunos da UFPR divulgados na última estatística da universidade, que foi de 41.018 . A terceira etapa desta fase comtemplou a simulação da ferramenta piloto, que ocorreu no dia 28/05/2019, com 24 alunos da turma do quinto semestre do curso de engenharia florestal da UFPR. A turma foi contextualizada sobre um projeto em andamento que caracterizava um conflito ambiental existente. $\mathrm{O}$ conflito selecionado para todas as aplicações da ferramenta foi o projeto intitulado Faixa de Infraestrutura de Pontal do Paraná.

Os alunos foram divididos em dois grupos iguais e assumiram papéis de atores diferentes, sendo eles, o grupo favorável a execução do projeto e construção do empreendimento e o grupo favorável a revisão e alteração do projeto antes da sua execução. Durante a simulação, os grupos passaram por uma contextualização da situação, com os dados do estudo e relatório de impacto ambiental (EIA/RIMA) do projeto, depois participaram de duas rodadas de negociação, a primeira sem o auxílio da ferramenta elaborada e a segunda com a cartilha desenvolvida a partir da ferramenta criada por esta pesquisa. Durante a simulação, tanto os alunos como os avaliadores especialistas responderam aos questionários. Após a análises prévia das respostas, para verificação da necessidade de alguma alteração, a ferramenta seguiu para uma nova aplicação.

A segunda aplicação foi realizada em uma turma especial do curso de Agronomia da UFPR, a disciplina era intitulada como Conceitos básicos de ciência rural e envolvia alunos de diferentes períodos de graduação do curso de agronomia da UFPR. A dinâmica ocorreu no dia 08/07/2019 e contou com 10 alunos participantes. A terceira aplicação, foi realizada com alunos do Programa de Pós-Graduação em Meio Ambiente Urbano e Industrial (PPGMAUI), na disciplina de Seminários, também dentro da UFPR. Contou com a presença de 26 alunos e aconteceu no dia 25/07/2019.

A última etapa desta fase contou com uma segunda abordagem para validação da ferramenta, feita por avaliadores externos a dinâmica. Todas as rodadas de negociações realizadas com as turmas foram gravadas e posteriormente foram elaborados dois vídeos distintos. Um vídeo relatava a rodada de negociação onde não foi aplicada a ferramenta desenvolvida neste trabalho e outro vídeo a negociação com 
a aplicação da ferramenta. Esses vídeos não foram identificados. $O$ grupo de avaliadores externo foi dividido em dois e cada grupo recebeu um material diferente, o grupo 1 recebeu o vídeo sem a aplicação da ferramenta e o grupo 2 o vídeo com a utilização da ferramenta desenvolvida, porém, não foram informados se o material quer receberam possuía ou não algum direcionamento para a discussão. Junto com o vídeo eles também receberam um questionário. Este processo de validação foi elaborado para eliminar a possibilidade de haver algum tipo de tendenciosidade nas conclusões da validação anterior.

A última fase do trabalho avaliou qualitativa e quantitativamente a melhoria do conflito ambiental existente, da comunicação e dos processos de argumentação das equipes após a utilização do modelo proposto. Esta avaliação foi baseada na análise das respostas provenientes dos questionários aplicados aos avaliadores especialistas, avaliadores externos e alunos envolvidos nas três aplicações da ferramenta elaborada. Os dados quantitativos foram avaliados conforme os parâmetros estatísticos: média, mediana, variância, desvio padrão e intervalo de confiança. E os dados qualitativos, ou seja, todas as respostas subjetivas obtidas através de qualquer um dos questionários foram lidos e analisados de modo individual e agrupadas quando semelhantes.

A última etapa desta fase foi a análise dos resultados gerais. O principal critério levado em consideração na análise foi a redução dos conflitos ambientais existentes e a melhoria dos processos de comunicação envolvidos. O que pode ser constatado através das respostas positivas dos participantes e avaliadores.

\section{RESULTADOS E DISCUSSÃO}

Baseado na metodologia apresentadas, foram identificados 54 conteúdos de programação neuroliguística. O Quadro 1 apresenta a lista detalhada destes conteúdos.

Quadro 1: Conteúdos de PNL identificados na pesquisa.

\begin{tabular}{|c|c|c|}
\hline Acuidade Sensorial & Linhas Temporais & Pistas Oculares \\
\hline Ancoragem & Links Linguísticos & Posições perceptuais \\
\hline Associação e Dissociação & Mapa Mental & Posições Psicogeográficas \\
\hline Backtraking & Mapas (Modelo de Mundo) & $\begin{array}{l}\text { Pressupostos da Programação Neurolinguística } \\
\text { (PNL) }\end{array}$ \\
\hline Bases da Hipnose & Meta Programas & Química do Cérebro \\
\hline Calibragem & Metáfora & Rapport \\
\hline Crenças - Para Onde Olhamos & Metamodelo & Reestruturação em Seis Passos \\
\hline Critérios e Valores & Missão de Vida & Relação entre Metamodelo e Linguagem de Milton \\
\hline Ecologia & Modelos de Aprendizagem & Resignificação \\
\hline Estados Internos & Níveis Neurológicos & SAR - Sistema de Ativação Reticular \\
\hline Estratégia Disney de Criatividade & $\begin{array}{l}\text { Objetivos - Como } \\
\text { Estabelecer? }\end{array}$ & Sistemas Representacionais \\
\hline $\begin{array}{l}\text { Estrutura da Prática da Programação Neurolinguística } \\
\text { (PNL) }\end{array}$ & Padrões & Squash Visual \\
\hline Fases do Estado da Arte & Padrões de Distorção & Suavizadores Linguísticos \\
\hline Filtros & Padrões de Distorção & Submodalidades \\
\hline Fobias & Padrões de Generalizações & Swish \\
\hline Integração Entre Partes & Padrões de Generalizações & Técnica Alívio da Sintomática de Dor de Cabeça \\
\hline Internalização & Padrões de Omissão & Teoria do cérebro triuno \\
\hline Linguagem de Milton Erickson & Padrões de Omissão & TOTS - Testa - Opera - Testa - Saída \\
\hline
\end{tabular}

Alguns conteúdos são visivelmente observados como principais e indispensáveis dentro do assunto, pois, estiveram presentes em todas as fontes de referência relacionadas a PNL. Dos 54 conteúdos totais, 9 
foram selecionados para compor a ferramenta, conforme os critérios apresentados na metodologia, de maneira a tornar o processo mais cíclico e aplicável (Quadro 2).

Quadro 2: Conteúdos selecionados para elaboração da ferramenta.

\begin{tabular}{|l|}
\hline Suavizadores \\
\hline Posições perceptuais \\
\hline Estados internos emocionais \\
\hline Ressignificação \\
\hline Rapport \\
\hline Metamodelo \\
\hline Sistemas representacionais \\
\hline Valores e critérios de valores \\
\hline Teoria do cérebro triuno \\
\hline
\end{tabular}

Além dos critérios algumas afirmações de renomados escritores sobre PNL atestam a importância destes conteúdos. Com base nesses conteúdos, a estrutura da ferramenta desenvolvida pode ser visualizada no fluxograma da Figura 1, divido em 3 fases contendo os 9 conteúdos selecionados. Na primeira fase da ferramenta são contemplados conteúdos de entendimento dos valores importantes para o grupo e as visões do problema através de vários ângulos. Na segunda fase, são contemplados conteúdos de preparação dos argumentos a serem defendidos, de maneira a obter melhores resultados. E a terceira fase consiste na aplicação das estratégias preparadas com os conteúdos da PNL, auxiliando para manter os bons relacionamentos entre as partes durante a arguição.
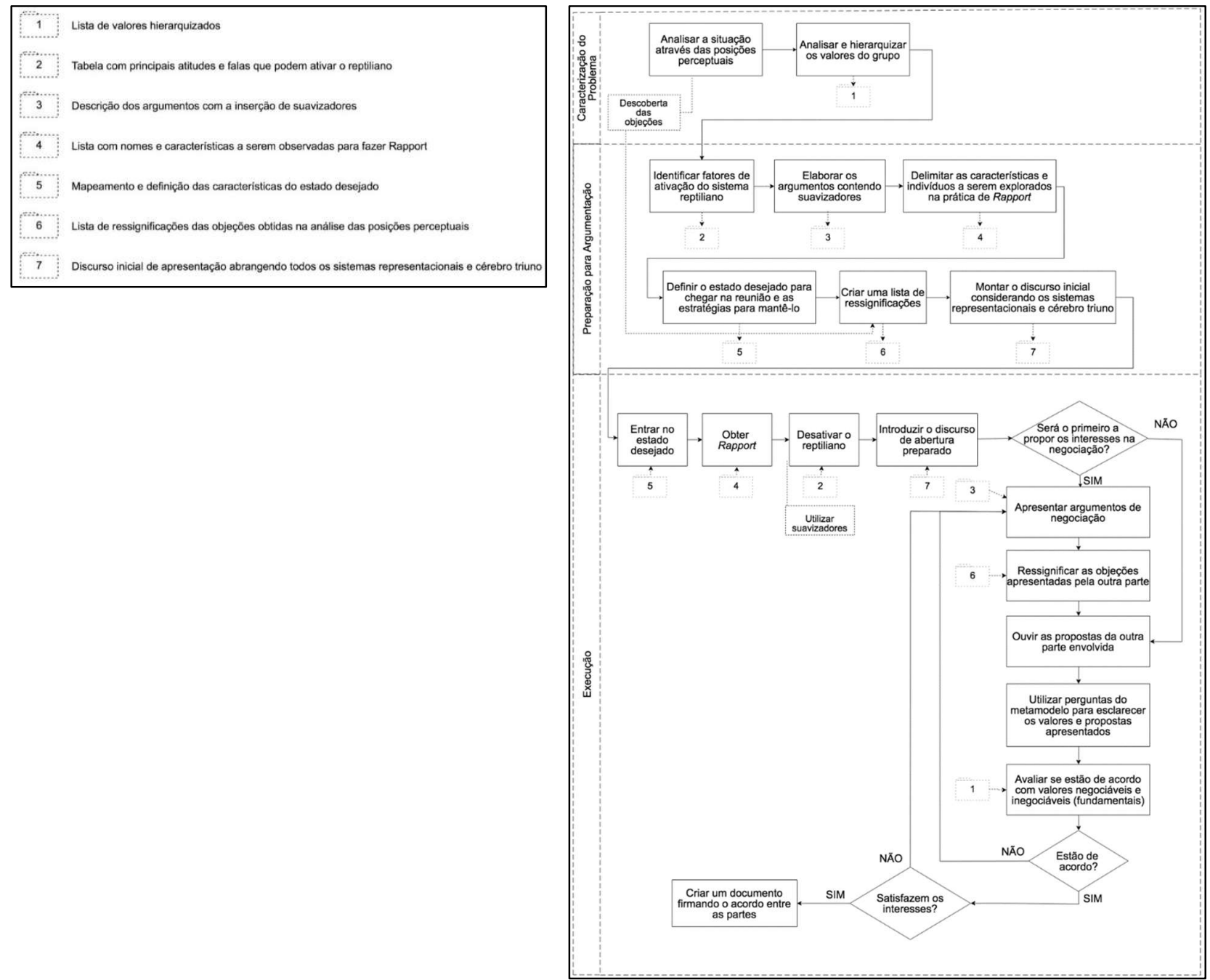

Figura 2: Fluxograma da ferramenta. 
Para execução do processo, esta ferramenta foi estruturada em formato de cartilha, com linguagem facilitada e campos próprios para preenchimento das informações requeridas. Ela foi dividida em 2 documentos, a cartilha de execução e o tutorial da ferramenta. Os documentos completos foram ilustrados e detalhados.

Após a elaboração da ferramenta foi realizada a sua verificação. Tanto na etapa de verificação como nas avaliações para validação da ferramenta é importante levar em consideração que estas atividades foram desenvolvidas com base em simulações de conflito ambiental, nas quais os reais envolvidos não se faziam presente, somente os alunos participantes da dinâmica.

Desta forma, a interpretação dos resultados deve levar este ponto em consideração, visto que alguns fatores presentes em uma situação real de conflito não puderam ser replicados durante a dinâmica. Como possibilidade para a continuação desta pesquisa, a ferramenta deve ser aplicada em uma negociação real, para refinamento e sua completa validação.

O cálculo amostral resultou em 57 de amostras necessárias para que a pesquisa se tornasse representativa dentro do universo de alunos da UFPR. A pesquisa contemplou um universo total de 59 alunos, representados conforme Tabela 1.

Tabela 1: Idade e gênero por grupo amostral.

\begin{tabular}{|l|l|l|l|l|l|}
\hline \multirow{2}{*}{ Turma } & \multicolumn{2}{|l|}{ Feminino } & \multicolumn{2}{l|}{ Masculino } & \multirow{2}{*}{ Média de Idade (Anos) } \\
\cline { 2 - 6 } & No & \% & No & $\%$ & \\
\hline Grad. Eng. Florestal & 13 & 54 & 11 & 46 & 18,7 \\
\hline Grad. Agronomia & 3 & 30 & 7 & 70 & 27,3 \\
\hline Pós-Graduação MAUI & 10 & 40 & 15 & 60 & 34,2 \\
\hline TOTAL & 26 & 44 & 33 & 56 & 26,7 \\
\hline
\end{tabular}

Foi possível observar que a divisão de gênero foi mais igualitária na primeira turma e mais divergente na segunda, porém, durante os processos de negociação essa diferença não se destacou e não influenciou o andamento da atividade, visto que em todas as turmas representantes de ambos os sexos se manifestaram e tiveram liberdade para expor os seus pontos de vista.

A diferença de idade entre as turmas foi mais expressiva devido ao período da graduação/pósgraduação em que se encontravam, mas esta diversidade foi um importante fator para validar a aplicação da ferramenta para diferentes públicos e faixas etárias. Todas as turmas conseguiram entender o funcionamento da cartilha apresentada.

Em relação aos interesses de cada um dos grupos, frente a situação de conflito apresentada na dinâmica (a construção da faixa de infraestrutura), foi percebida uma preferência dos alunos das turmas de engenharia florestal e pós-graduação em meio ambiente em defesa da não execução do projeto. Já a turma de agronomia apresentou uma tendência mais voltada ao favorecimento da construção do projeto. Essas diferenças foram pontuais e certificaram a ferramenta quanto a sua utilização em todas as ocasiões.

Os alunos foram direcionados a classificar de 1 (nada) a 5 (muito) qual a foi o nível de contribuição da cartilha para a esta melhoria dos relacionamentos durante a segunda rodada de negociação, que ocorreu com a utilização da ferramenta desenvolvida. A Figura 3 mostra que $41 \%$ dos alunos participantes da dinâmica classificaram a contribuição da ferramenta com a nota 5 e $44 \%$ responderam com nota 4 . Desta 
forma $85 \%$ dos participantes da dinâmica corroboraram com a hipótese de melhoria dos relacionamentos e dos processos de comunicação a partir da utilização da ferramenta desenvolvida nesta pesquisa.

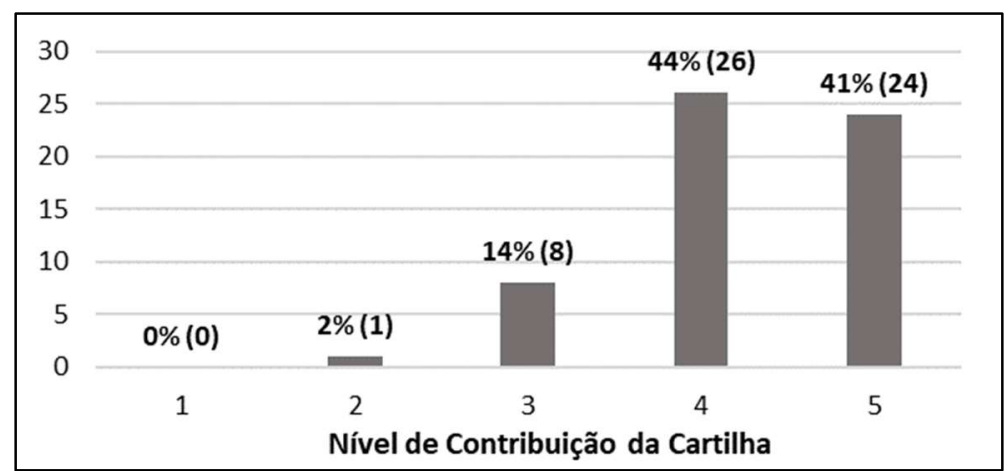

Figura 3: Nível de contribuição da cartilha para melhoria dos relacionamentos.

A Figura 4 apresenta as respostas do nível de contribuição da ferramenta divididas por grupo amostral. Foi possível observar que conforme houve o aumento do nível de especialização e o avanço de idade das turmas o grupo de respostas passou a ser mais heterogêneo, o que pode ter ocorrido devido ao aprimoramento do senso crítico dos avaliadores.

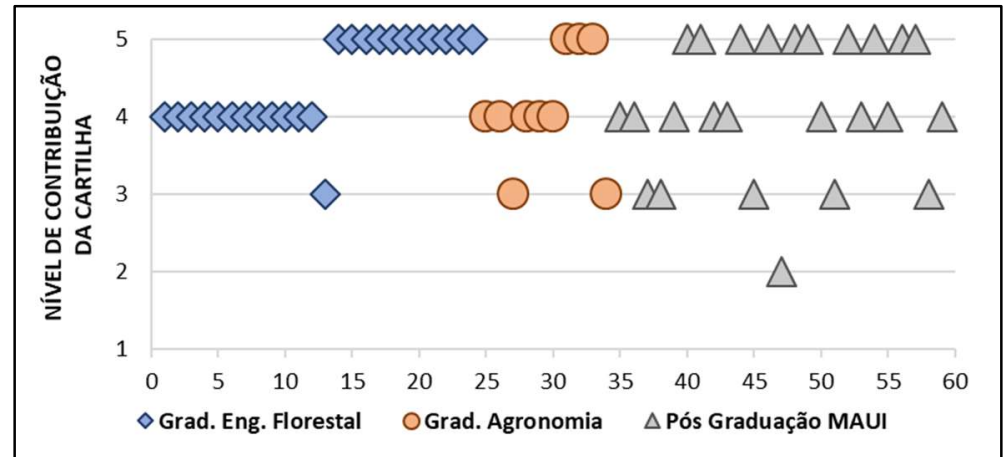

Figura 4: Nível de contribuição da cartilha por grupo amostral.

Analisando as estatísticas das notas obtidas, obteve-se uma média total de 4,24 para o nível de contribuição da cartilha na melhoria dos relacionamentos. A média por grupo amostral variou após a primeira casa decimal, porém, também se manteve no nível 4, da mesma forma que a mediana, total e por turma, apresentou nota 4 (Tabela 2).

Tabela 2: Estatísticas dos níveis de contribuição da ferramenta.

\begin{tabular}{|l|l|l|l|l|l|l|}
\hline Turma & $\begin{array}{l}\text { No de } \\
\text { respostas }\end{array}$ & Média & Mediana & Variância & Desvio padrão & Intervalo de confiança \\
\hline Grad. Eng. Florestal & 24 & 4,42 & 4,00 & 0,34 & 0,58 & $3,83-5,00$ \\
\hline Grad. Agronomia & 10 & 4,10 & 4,00 & 0,54 & 0,74 & $3,36-4,84$ \\
\hline Pós Graduação MAUI & 25 & 4,12 & 4,00 & 0,78 & 0,88 & $3,24-5,00$ \\
\hline TOTAL & 59 & 4,24 & 4,00 & 0,56 & 0,75 & $3,49-4,99$ \\
\hline
\end{tabular}

Como já era esperado, a variância e o desvio padrão da turma de pós-graduação apresentou os maiores valores, respectivamente, 0,78 e 0,88. Já a turma de graduação em engenharia florestal apresentou os menores valores para estes dois parâmetros, sendo eles 0,34 e 0,58 , respectivamente. Os valores de variância e desvio padrão amostral dos dados totais foram de 0,56 e 0,75. O desvio padrão consiste na raiz quadrada da variância e quanto menores os seus valores, mais próximos da média estes valores se encontram 
(TRIOLA, 2017). Considerando a média de notas 4,24 e desvio padrão de 0,75 , obtido através de diferentes públicos que compõem a amostra, o intervalo de confiança para as notas dos alunos da UFPR é 3,49 a 4,99. Desta maneira fica perceptível a contribuição da ferramenta para a melhoria dos relacionamentos e dos processos de comunicação durante negociações relacionadas a conflitos ambientais.

A segunda etapa de validação da ferramenta contou com a avaliação feita pelos dois professores especialistas. Eles analisaram as duas rodadas de negociação de cada uma das três aplicações da ferramenta. A Figura 5 apresenta as percepções que os avaliadores obtiveram em relação as rodadas de negociações, sendo a primeira rodada, sem a ferramenta, representada como N1 e a segunda rodada, com a ferramenta, representada como $\mathrm{N} 2$.

Foi observado na comparação entre a negociação sem a ferramenta (N1) e a negociação com a ferramenta elaborada (N2), que todos os critérios avaliados obtiveram melhoria nas classificações. O critério agradabilidade da discussão, que na negociação 1 possuía 3 avaliações insatisfatórias, na negociação 2 apresentou 4 avaliações 'ótima' e 2 'satisfatória'. O critério 'boa convivência', eliminou as 2 avaliações 'insatisfatória' observadas na negociação 1 e expôs 4 avaliações 'ótima' na negociação 2. Por sua vez, o critério clareza na discussão substituiu as duas avaliações 'insatisfatória' presentes na primeira negociação por 1 avaliação 'ótima' e outra 'satisfatória' na negociação 2.

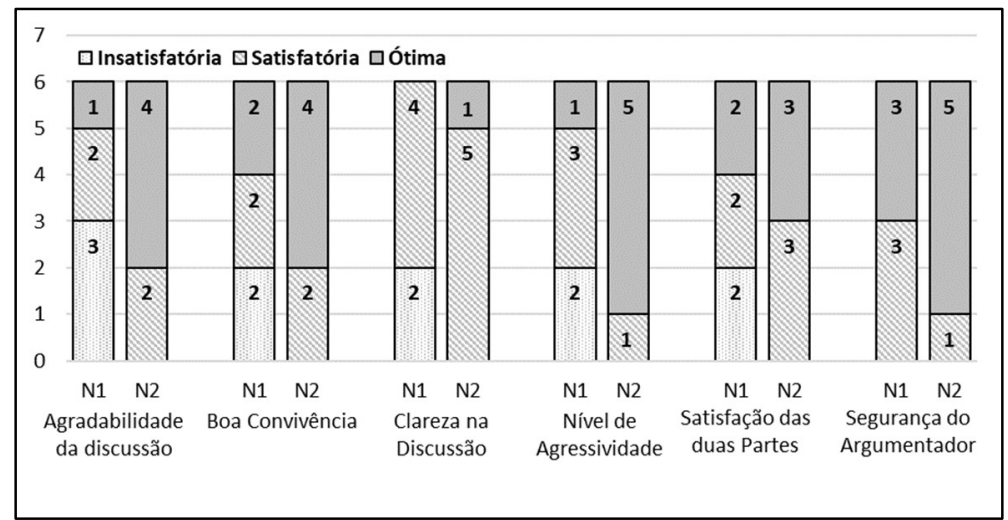

Figura 5: Comparação dos critérios entre as rodadas de negociação - avaliadores especialistas.

Quanto ao nível de agressividade os resultados foram expressivos, na negociação 1 a avaliação apresentou 2 percepções 'insatisfatória', 3 'satisfatória' e 1 'ótima', já na segunda negociação 5 avaliações classificaram o critério como 'ótima' e 1 como 'satisfatório'. A satisfação entre as partes também foi aumentada na dinâmica que compreendeu a utilização da ferramenta, as duas avaliações 'insatisfatória' da primeira rodada de negociação sumiram e deram lugar a uma avaliação equilibrada na segunda rodada, com 3 percepções 'satisfatória' e 3 'ótima'.

Por fim, o critério segurança do argumentador também foi incrementado, de modo que 3 avaliações 'ótima' na rodada N1 deram lugar a 5 avaliações 'ótima' na rodada N2. Desta forma, baseado na avaliação desenvolvida pelos professores especialistas, é possível afirmar que a ferramenta elaborada nesta pesquisa pode auxiliar na melhora dos processos de comunicação e dos relacionamentos que envolvem conflitos ambientais.

A Tabela 3 apresenta as mesmas avaliações dos professores em relação à segunda rodada de 
negociações, porém dividas com especialidade do avaliador. É possível observar que eles divergem pouco e a diferença aparece nos quatro últimos critérios, sempre com uma alteração máxima de 1 avaliação, que vara entre os critérios 'satisfatório' e 'ótimo'.

Tabela 3: Avaliação da negociação com a ferramenta apresentada por especialidade.

\begin{tabular}{|l|l|l|l|l|l|l|}
\hline \multirow{2}{*}{ Critério } & \multicolumn{3}{l|}{ Especialista em Conflitos } & \multicolumn{3}{l|}{ Especialista em PNL } \\
\cline { 2 - 7 } & Insatis. & Satis. & Ótima & Insatis. & Satis. & Ótima \\
\hline Agradabilidade da discussão & 0 & 1 & 2 & 0 & 1 & 2 \\
\hline Boa convivência & 0 & 1 & 2 & 0 & 1 & 2 \\
\hline Clareza na discussão & 0 & 3 & 0 & 0 & 2 & 1 \\
\hline Nível de agressividade durante a interação & 0 & 1 & 2 & 0 & 0 & 3 \\
\hline Satisfação das partes em relação as demandas & 0 & 2 & 1 & 0 & 1 & 2 \\
\hline Segurança do argumentador & 0 & 1 & 2 & 0 & 0 & 3 \\
\hline TOTAL & 0 & 9 & 9 & 0 & 5 & 13 \\
\hline
\end{tabular}

Assim, pode-se atestar que não houveram tendências de melhoria somente em uma das especialidades, conflitos ambientais ou comunicação através da neurolinguística, e sim em ambos os processos.

A terceira etapa de validação foi feita pelos dois grupos de avaliadores externos que receberam um vídeo da primeira ou da segunda rodada de negociação sem identificação. A Figura 6 mostra a comparação entre as avaliações feitas pelos dois diferentes grupos. As notas atribuídas pelo grupo que recebeu o vídeo da negociação sem a ferramenta estão indicadas como N1 e as notas do grupo que recebeu o vídeo com a negociação que utilizou a ferramenta estão identificadas como N2.

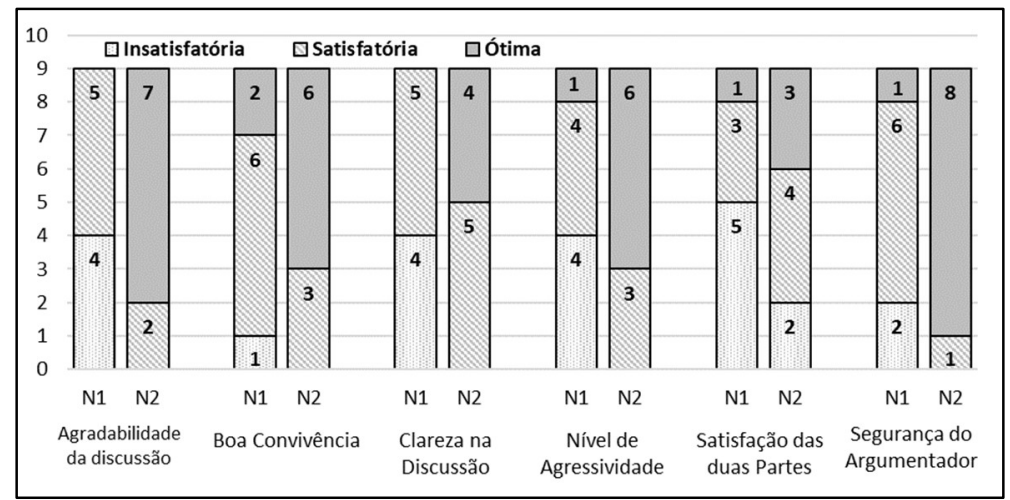

Figura 6: Comparação dos critérios entre as rodadas de negociação - avaliadores externos.

A melhoria entre os relacionamentos pode ser percebida forma clara pelas comparações entre as avaliações de cada um dos critérios relacionados com a primeira e a segunda rodada de negociação. Com exceção do critério satisfação entre as partes, todos os outros 5 critérios que apresentaram alguma avaliação classificada como 'insatisfatória' durante a primeira negociação, substituíram as avaliações desta categoria por avaliações nas categorias 'satisfatória' e 'ótima' durante a segunda rodada de negociação, que aconteceu com a utilização da ferramenta.

O critério agressividade da discussão, que na avaliação da primeira rodada de negociação não possuía nenhuma avaliação na categoria 'ótima' passou a ter 7 avaliações nesta categoria na segunda rodada. 0 critério 'boa convivência' que possuía 1 resposta 'insatisfatória', 6 'satisfatória' e 2 'ótima' na negociação 1 apresentou uma resposta positiva na negociação 2, representada por 3 classificações como 'satisfatória' e 6 
como 'ótima'. Em relação a clareza na discussão a primeira negociação obteve a percepção de 4 avaliadores como 'insatisfatória' e 5 como 'satisfatória', já na segunda negociação, 5 avaliadores classificaram como 'satisfatória' e 5 como 'ótima'.

Em relação ao nível de agressividade, a negociação 1 apresentou 4 respostas como 'insatisfatória', 4 como 'satisfatória' e 1 como 'ótima', na negociação 2, 3 respostas foram classificadas como 'satisfatória' e 6 como 'ótima'. O critério satisfação entre as partes apresentou uma redução das classificações como 'insatisfatória' de 5 para 2, entre as negociações 1 e 2 respectivamente. 0 mesmo aconteceu com a classificação 'ótima', que passou de 1 para 3 neste critério. Já a segurança do argumentador obteve um aumento expressivo na categoria 'ótima', que passou de 1 para 8 avaliações entre as duas negociações.

Com a finalidade explicitar e analisar de maneira mais ampla e facilitada as diferenças entre as avaliações e os impactos da ferramenta nos processos de comunicação dentro dos conflitos ambientais, foram atribuídos pesos para cada uma das opções de avaliação, sendo 1 para 'insatisfatória' 2 para 'satisfatória' e 3 para 'ótima'. A Figura 7 apresenta os resultados desta abordagem.

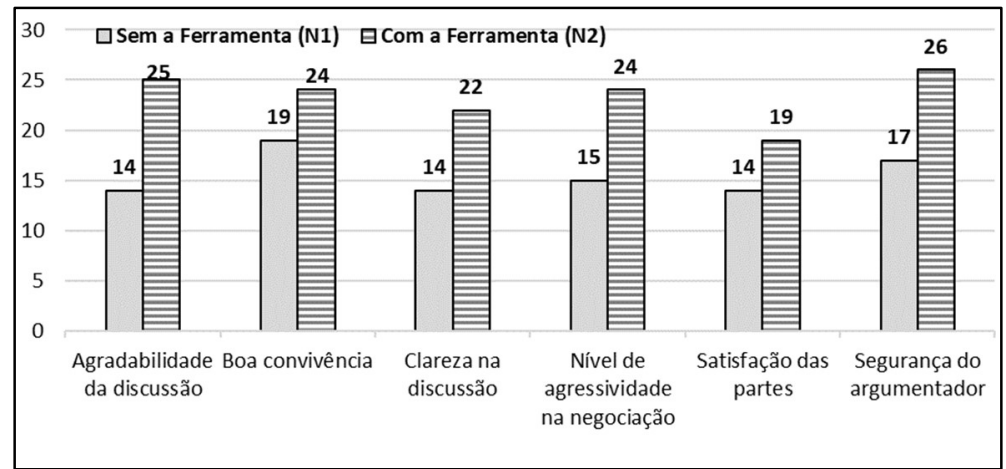

Figura 7: Atribuição de pesos as critérios de avaliação nas negociações.

Por meio dos pesos atribuídos é possível observar que ambas as negociações pontuaram, isso ocorre, pois, de uma forma ou de outra as pessoas já sabem iniciar uma negociação. $O$ interessante foi observar o potencial de melhoria alcançado com a ferramenta. A maior diferença de pontuação apresentou-se no critério de agradabilidade da discussão, com um delta de 11 pontos. Na sequência, com 9 pontos de discrepância apareceram os critérios nível de agressividade e segurança do argumentador. Estes 3 critérios foram os que sofreram maiores impactos positivos com a utilização da ferramenta.

Os 3 critérios menos expressivos foram clareza na discussão, boa convivência e satisfação entre as partes, com diferenças de 8, 5 e 5 pontos respectivamente. As respostas discursivas destes avaliadores reforçam os resultados obtidos pela comparação dos critérios anteriores e atestam a validade da ferramenta para a melhorias dos processos de comunicação e dos relacionamentos que envolvem negociações a respeito de conflitos ambientais. No Quadro 3 foram compiladas algumas respostas de integrantes de cada grupo.

É importante salientar que a ferramenta foi avaliada com base em uma simulação de conflito, neste caso, é primordial levar em consideração que os resultados apresentados possuem uma primeira perspectiva dos potenciais da ferramenta e não a avaliação na sua totalidade, que posteriormente deve ser realizada com participantes de uma negociação real dentro de um conflito. 
Quadro 3: Respostas discursivas dos avaliadores externos.

\begin{tabular}{|l|l|}
\hline $\begin{array}{l}\text { Respostas de quem viu o vídeo sem } \\
\text { a aplicação da ferramenta }\end{array}$ & Respostas de quem viu o vídeo com a aplicação da ferramenta \\
\hline $\begin{array}{l}\text { 'Não havia preocupação com o } \\
\text { ponto de vista do outro.' }\end{array}$ & $\begin{array}{l}\text { 'Todos se mantiveram calmos e expuseram seus pontos de vista de forma clara apesar } \\
\text { das diferentes opiniões.' }\end{array}$ \\
\hline $\begin{array}{l}\text { 'Não tinha uma sequência lógica na } \\
\text { discussão.' }\end{array}$ & 'Houve respeito para com a opinião do outro, sem agressividade e perda de controle.' \\
\hline 'A discussão ficou confusa.' & $\begin{array}{l}\text { 'Compreensão por parte de cada grupo, empatia pela opinião alheia, clareza nas } \\
\text { informações passadas.' }\end{array}$ \\
\hline $\begin{array}{l}\text { 'Aumento na agressividade entre as } \\
\text { partes.' }\end{array}$ & $\begin{array}{l}\text { 'Explicavam muito bem, de forma segura, os seus pontos de vista. A discussão se deu de } \\
\text { forma 'civilizada', sem ofensas e agressões.' }\end{array}$ \\
\hline $\begin{array}{l}\text { 'Muitas pessoas falando ao mesmo } \\
\text { tempo, agressividade e poucos } \\
\text { momentos de empatia.' }\end{array}$ & $\begin{array}{l}\text { 'Os participantes estavam atentos a fala do outro, sequência de argumentação lógica, } \\
\text { cordialidade entre os participantes, reforço da importância do diálogo e do encontro de } \\
\text { um denominador comum entre as partes.' }\end{array}$ \\
\hline
\end{tabular}

Ao final das três avaliações, que englobaram os participantes diretos da dinâmica (alunos), os avaliadores especialistas, que acompanharam todas as etapas da aplicação da ferramenta, e os avaliadores externos, que receberam um material não tendencioso e parcial da negociação, pode-se afirmar que a ferramenta proporcionou a melhoria na resolução de conflitos ambientais e na comunicação entre os diversos atores.

Isso pode ser confirmado pelos alunos quando, os mesmos apontaram uma média do nível de contribuição para melhoria dos relacionamentos de 4,24, sendo a nota máxima 5 . Pelos professores especialistas isso foi comprovado principalmente pela melhoria de todos os critérios avaliados entre a primeira e a segunda rodada de negociações. Além disso, as respostas tanto do especialista em comunicação e programação neurolinguística como da especialista em conflitos ambientais não apresentou grandes diferenças e variações.

Pelos avaliadores externos, essa hipótese pode ser confirmada quando as notas relacionadas a cada critério se apresentaram mais altas para a negociação com a utilização da ferramenta do que para a negociação sem a aplicação da ferramenta. Somado as respostas discursivas com comentários positivos a respeito da rodada de negociação com a utilização do material elaborado.

Desta forma, a ferramenta atendeu seu principal objetivo. Na sequência é importante fazer aprimoramentos necessários, mas, a ferramenta já está formatada para ser utilizada em situações de conflitos ambientais, proporcionando melhoria nos relacionamentos e nos processos de comunicação envolvidos. Afinal, bons relacionamentos e processos de comunicação eficientes são pilares fundamentais para o sucesso de qualquer empreendimento e para a conservação de importantes reservas naturais.

\section{CONCLUSÕES}

Pela observação dos aspectos analisados pode-se perceber que a ferramenta elaborada auxiliou a resolução de conflitos ambientais e a melhoria da comunicação entre as partes envolvidas. A respeito do desenvolvimento de uma ferramenta prática para aplicação em conflitos ambientais, a cartilha elaborada atendeu as expectativas e foi bem aceita pelo público participante das simulações.

As validações da ferramenta atenderam às expectativas, de modo a eliminar a tendenciosidade e atenderem a avaliação do objetivo principal. As 3 etapas de validação, que contemplaram públicos que 
observavam a ferramenta de três prismas diferentes trouxeram maior segurança e credibilidade acerca dos resultados obtidos.

A avaliação da eficácia da ferramenta nos processos de resolução de conflitos ambientais foi positiva e atendeu as expectativas inicias, porém, cada conflito possui a sua própria dinâmica e a relação sistêmica de cada participante dentro do processo, bem como seu entendimento das ferramentas, pode influenciar o desfecho de cada conflito.

Em síntese, verificou-se que os conflitos ambientais estão presentes em todas as esferas sociais e econômicas, mas, apesar da sua dinamicidade, alguns processos de comunicação são comuns a todas as negociações, se bem trabalhados podem auxiliar na melhoria dos relacionamentos e resolução dos conflitos. Os desafios a cerca deste tema são extensos, visto que o estudo dos processos de comunicação ainda não é uma prioridade ou não está tão acessível a toda população.

Desta forma a ferramenta visou aproximar e simplificar estes conceitos e técnicas para que qualquer pessoa possa compreender e auxiliar na resolução dos conflitos ambientais que a cerca.

Tratar de conflitos ambientais não é um tema simples, pois, além da individualidade de cada conflito, cada vez mais a população mundial cresce e as tensões e interesses que envolvem a utilização de um certo recurso aumentam. Assim, uma ferramenta que possibilita a melhoria das discussões sobre estes temas é um passo inicial para auxiliar e abrir portas a novos desafios. Como sugestão para novas pesquisas, a aplicação da ferramenta em situações de conflitos reais que passam por processos de negociação irá permitir de fato uma avaliação completa da ferramenta.

\section{REFERÊNCIAS}

ABNT. Asoociação Brasileira de Normas Técnicas. NBR ISO 14.001: Sistema de Gestão Ambiental. Rio de Janeiro, 2015.

ANDREAS, S.. Neuro-Linguistic Programming (NLP): Changing Points of View. The Family Journal, v.7, n.1, p.22-28, 1999. DOI: https://doi.org/10.1177/1066480799071004

ARIAS, P. G.. Aproximaciones conceptuales y metodológicas al conflicto social. In: Comunidades y conflcitos socioambientales: experiencias y desafríos en América Latina. Quito: ABYA-YALA, 1999. p.35-88.

BANDLER, R.; GRINDER, J.. Sapos em príncipes: Programação Neuro linguística. 11 ed. São Paulo: Summus, 1982.

DILTS, R.. A estratégia da genialidade. São Paulo: Summus, 1998.

DOWLEN, A.. NLP - help or hype? Investigating the uses of neuro-linguistic programming in management learning. Career Development International, v.1, n.1, p.27-34, 1996. DOI: https://doi.org/10.1108/13620439610111408

FONSECA, B.; OLIVEIRA, M.; SOUSA, D.. Conflitos Ambientais: Atores, Causas e Desdobramentos na Zona da Mata Mineira. Caminhos de Geografia, Uberlândia, v.13, n.42, p.283-299, 2012.

NASCIMENTO, E. M.; EL SAYED, K. M.. Gestão do Capital
Humano/FAE Business Schol. Curitiba: Gazeta do povo, 2002.

O'CONNOR, J.. Manual de Programação Neurolinguística: PNL: um guia prático para alcançar os resultados que você quer. 11 ed. Rio de Janeiro: Qualitymark, 2015.

O'CONNOR, J.; SEYMOUR, J.. Treinando com a PNL: recursospara administradores, instrutores e comunicadores. 3 ed. São Paulo: Summus, 1996.

ORTIZ, P.. Apuntes teórico-conceptuales para el diseño de una propuesta metodológica de manejo de conflictos socioambientales a través de la forestería comunitaria. In: Comunidades y conflcitos socioambientales: experiencias y desafríos en América Latina. Quito: ABYA-YALA, 1999. p.734.

SUÁREZ, L. G.; TORO, B. L.; BARAJAS, C. D. R.; ZULUAGA, J.. Las agendas interinstitucionales ambientales: un instrumento para la resolución de conflictos ambientales. Rev. Estud. Soc., v.2, n.53, p.29-42, 2015. DOI: http://dx.doi.org/10.7440/res53.2015.02

TRIOLA, M. F.. Introdução à estatística. 12 ed. Rio de Janeiro: LTC, 2017.

WANDERLEY, L. J. M.. Conflitos e impactos ambientais na exploração dos recursos minerais da Amazônia. Dissertação 
(Mestrado em Geografia) - Universidade Federal do Rio de Janeiro, Rio de Janeiro, 2008.
WATHERN, P.. Environmental Impact Assessemet: Theory and Practice. London: Routledge, 1988.

A CBPC - Companhia Brasileira de Produção Científica (CNPJ: 11.221.422/0001-03) detém os direitos materiais desta publicação. Os direitos referem-se à publicação do trabalho em qualquer parte do mundo, incluindo os direitos às renovações, expansões e disseminações da contribuição, bem como outros direitos subsidiários. Todos os trabalhos publicados eletronicamente poderão posteriormente ser publicados em coletâneas impressas sob coordenação da Sustenere Publishing, da Companhia Brasileira de Produção Científica e seus parceiros autorizados. Os (as) autores (as) preservam os direitos autorais, mas não têm permissão para a publicação da contribuição em outro meio, impresso ou digital, em português ou em tradução. 